\title{
THE USE OF LASER SCANNING IN THE DESIGN AND BIM
}

D. Gura ${ }^{1}$, G. Shevchenko ${ }^{2}$, A. Rogozin ${ }^{3}$

DOI: http://doi.org/10.15350/L_26/8/22/22

\section{Abstract}

The article deals with the history of the essence of the work and the use of BIM and laser scanning. Examples of work both separately and together these systems. As well as to the conclusion that at present the leading technologies in the field of scanning a laser scanning and data processing and analysis is carried out in BIM.

Keywords: Laser scanning, BIM, Revit, the use of laser scanning in the BIM, technology.

Идея технологии ВІМ зародилась в 1962 году. В 1986 был первый официально зарегистрированный случай применения информационного моделирования зданий при реконструкции 3 терминала аэропорта Heatrow в Лондоне. Более 20 лет назад уже анализировали модели (BDA) по различным свойствам и параметрам. Например, влияние на атмосферу, выброс углекислого газа, освещенность и множество других анализируемых показателей. В 2000 году был создан Revit - программа, которая работает по ВІМ технологии. Создателем этой программы является Леонид Райз, который родился в Санкт-Петербурге, но в настоящее время проживает в Бостоне. [1]

Изначально многие опытные проектировщики переходили с бумаги на AutoCAD, при этом инструменты работы были весьма простыми: линия, слой, размер, текст. Они позволяли в AutoCAD успешно работать, при этом инструмент работы менялся, но логика оставалась прежней. Следовательно, проблемы остались прежние с сопутствующими последствиями.

Таким образом, появлялась необходимость в новой, более удобной и современной технологии, которой и стала BIM. BIM (Building Information Modeling) - цифровая копия здания. Главная идея технологии - создание элементов, которые имеют не только форму, но и важную информацию. С модели ВІМ можно получить чертежи, спецификации, графические данные и визуальную модель. [5] Так же можно в любом месте здания получить его разрез для дальнейшего анализа.

${ }^{1}$ Dmitry Gura, Candidate of Technical Sciences, Senior Lecturer, Kuban State Technological University, Russia.

${ }^{2}$ Grittel Shevchenko, assistant, Kuban State Technological University, Russia.

${ }^{3}$ Artem Rogozin, student, Kuban State Technological University, Russia. 


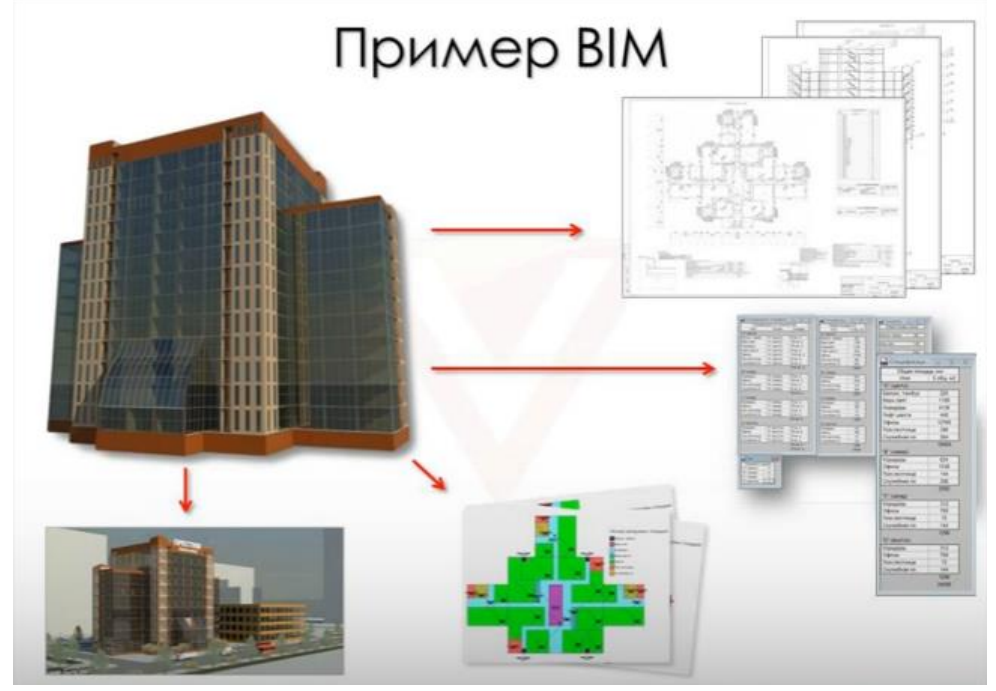

Рис. 1. Пример ВIM

Преимущество технологии BIM: высокая точность, наглядность, скорость, экономическая эффективность.

В настоящее время в западных странах большинство строительных компаний применяют лазерное сканирование в ВIM, однако в России оно только начинает распространяться. Технология поддерживается на государственном уровне и внедряется в систему высшего образования. Существует обучающий курс «Заметки o Revit» по данной системе моделирования, автором которого является Александр Высоцкий.

Неотъемлемой составляющей ВIM является наземное лазерное сканирование. Сканирование - измерительная геодезическая технология, которая позволяет получить обмеры реально существующих объектов в трёхмерном виде. [3]

Лазерный сканер - прибор, который при помощи лазерного луча осуществляет до 1 миллиона измерений в секунду, где каждое измерение имеет свое расположение в пространстве, координаты X, Y, Z. В итоге измерение получается массив данных под названием «облако точек», которое и представляет собой трехмерную модель изучаемого объекта [7-9].

Преимущества применения лазерного сканирования:

-Точность

-Скорость

-Детальность

- Совместимость с CAD и BIM

-Результат сразу в 3D

-Отсутствие человеческого фактора

-Сканирование вогнутых поверхностей 


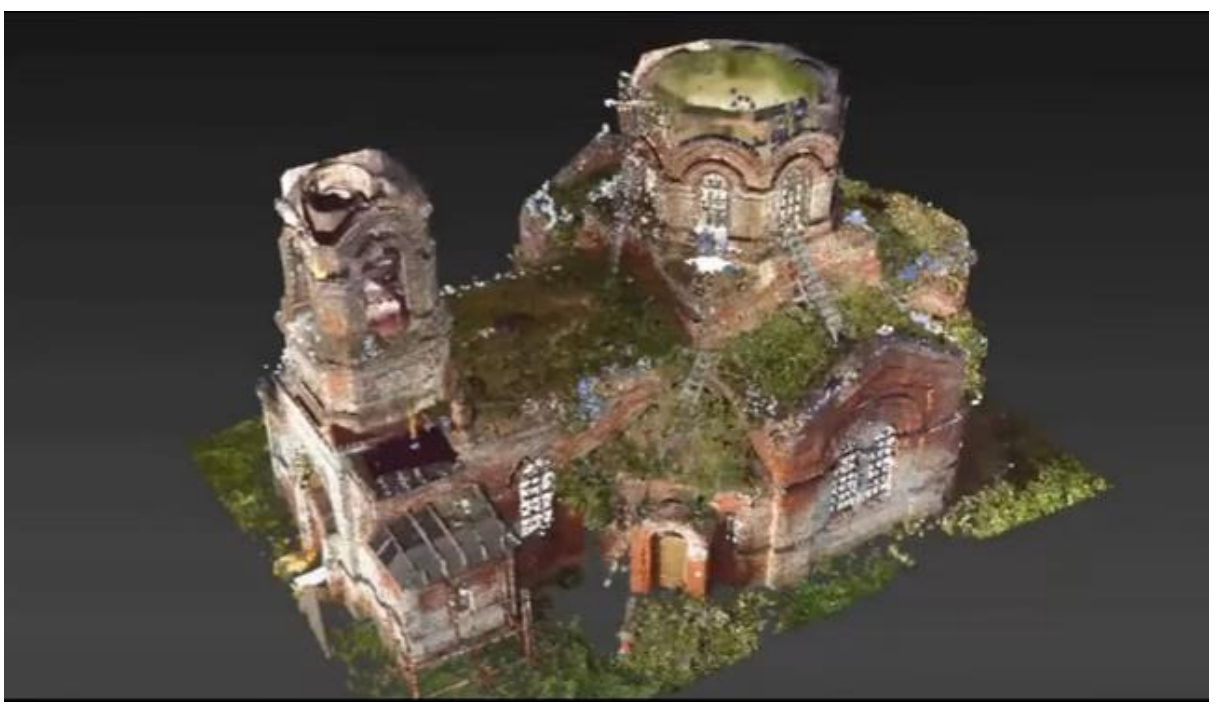

Рис. 2. Пример лазерного сканирования

Первые сканеры начали появляться в Западных странах в конце 90 х годов 20 века. Первые модели были громоздкими и крайне медленными, а также на тот момент не хватало компьютерной мощности для обработки большого количества информации. Однако в начале 2000 годов появилось программное обеспечение, которое было способно работать с таким массивом точек. [6] В России лазерные сканеры начали появляться с 2002 года.

Характеристики современного лазерного сканера на примере прибора Leica ScanStation P40 следующие [2]:

-Дальность: 270 м

-Скорость: 1 млн измерений в секунду

-Точность дальномера: 1.2мм + 10ppm

-HDR фотокамера

-Рабочая температура: от -20 до $+50{ }^{\circ} \mathrm{C}$

Таким образом, получив представление о лазерном сканировании и BIM, нужно связать эти системы для получения схемы работы. Первоначально происходит сканирование объекта при помощи лазерного сканера, далее сшивка и геопривязка данных, в итоге производится экспорт облаков точек и обработка данных уже в Autodesk Revit. [4]

Применение лазерного сканирования в BIM на примере работы Михаила Аникушкина. Объектом было двухэтажное здание с подвалом, находящееся по адресу ул. Петровский бульвар 17, г. Москва. Архитектором данного сооружения был Клейн, построено в 1917 году, часть объекта было жилым, а часть промышленным. 


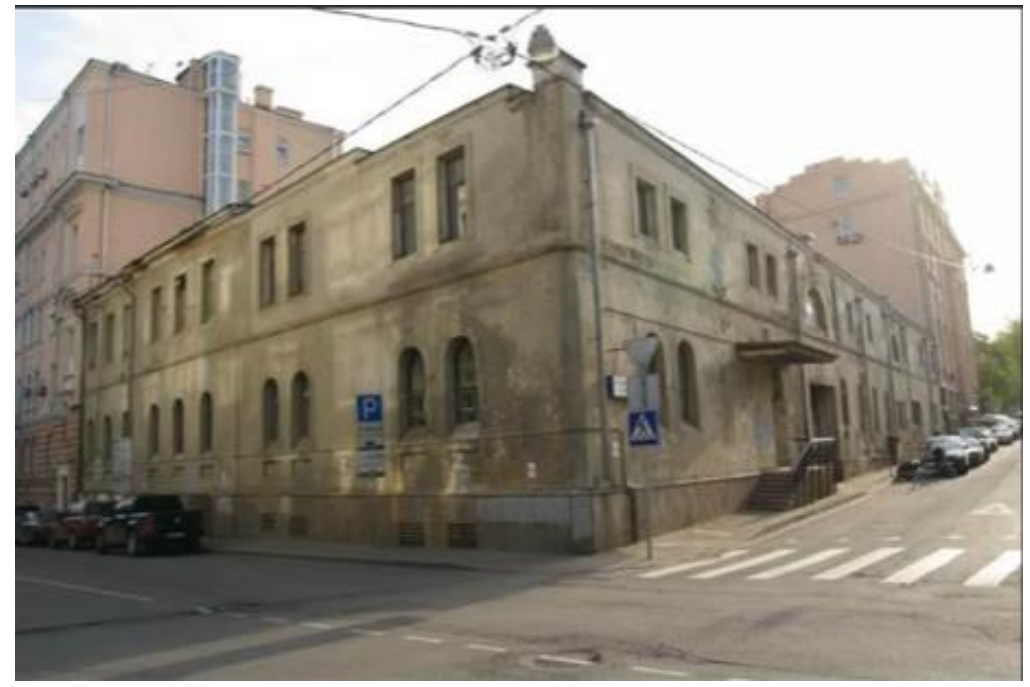

Рис. 3. Петровский бульвар, 17, Москва

Изначально проходил полевой этап при помощи лазерного сканирования прибором Leica P20. Площадь сканирования составила порядка 7000 м² $^{2}$ этажа, подвал, кровля). Сканирование было выполнено за 3 дня при использовании 2-х приборов. Было использовано 300 станций. Далее 5 дней камеральных работ-1 этап:

-Облако точек RCP

-Leica Truview

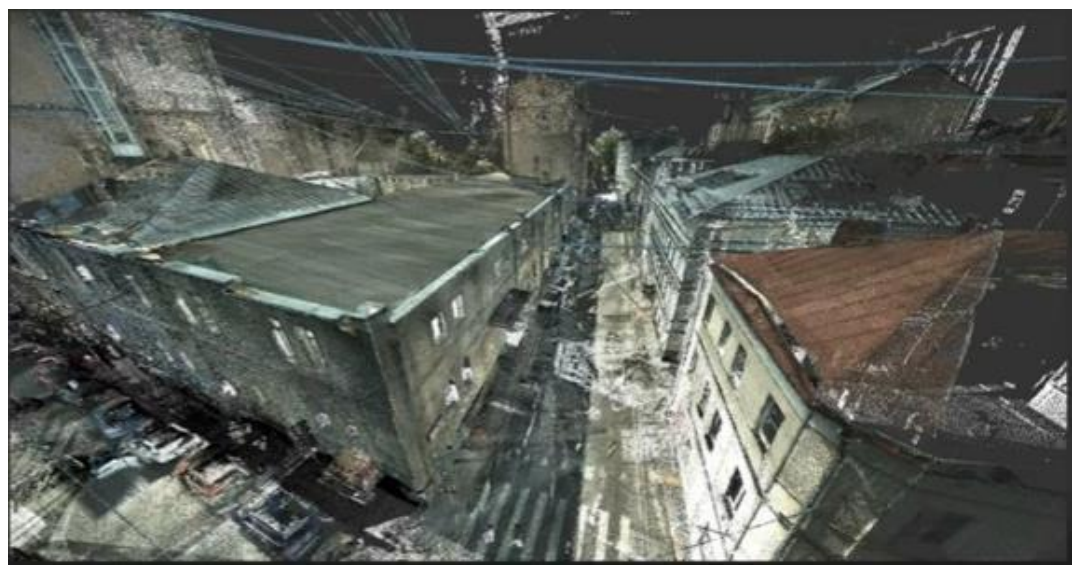

Рис. 4. Облако точек (необработанное) 


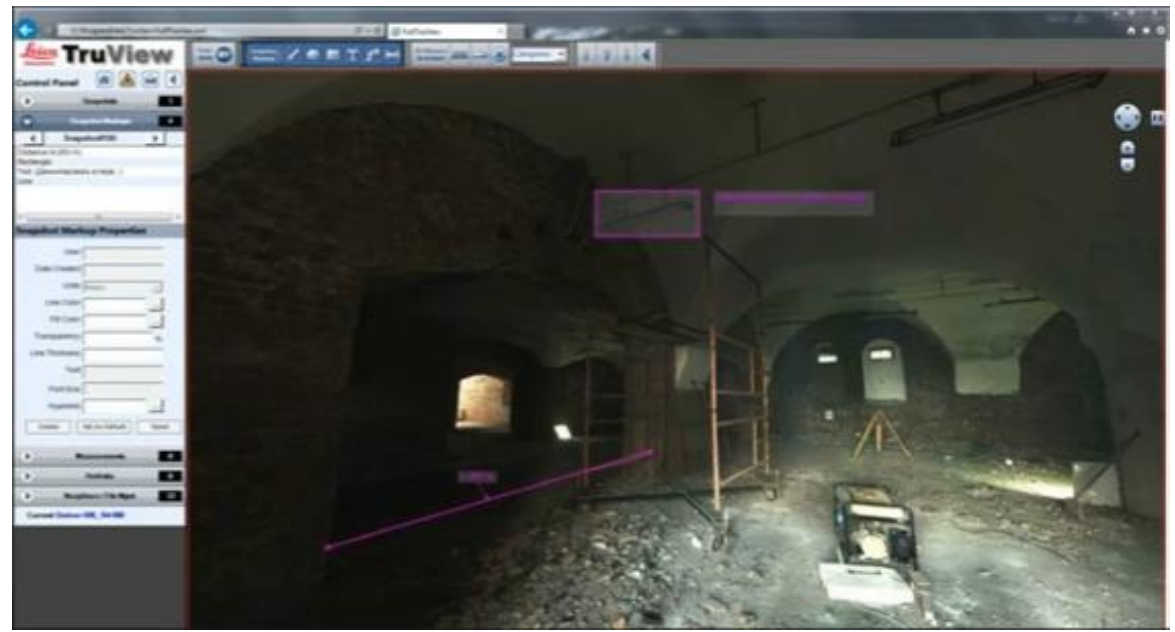

Рис. 5. Leica TruView

20 дней камеральных работ-2 этап (обмерные чертежи).

За месяц было выполнено моделирование в Autodesk Revit-3 этап

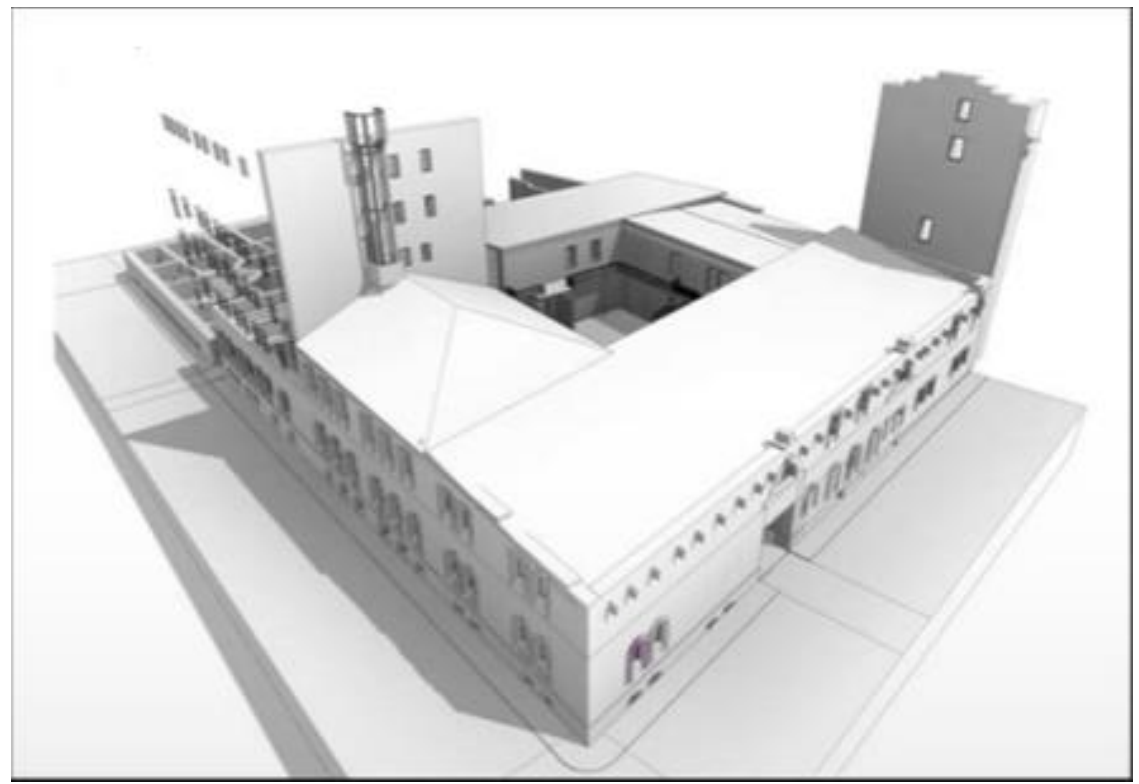

Рис. 6. Модель здания (созданная при помощи ВIM)

По итогу выполненной работы были сделаны выводы, что использование лазерного сканирования ускоряет процесс измерений примерно в 5 раз и результат был сразу в трехмерном измерении, в отличии, если бы работу осуществляли при помощи традиционных приборов, таких как тахеометр и рулетка. 
В современном мире лазерное сканирование и ВІМ необходимый атрибут развитых строительных кампаний. Возможности применения лазерного сканирования в ВIM: изыскания перед проектированием, обновление статуса строительно-монтажных работ, исполнительная съемка.

\section{References:}

[1] Сергей Котельников, Александр Высоцкий, Михаил Аникушкин. Вебинар: лазерное сканирование и ВIM в реальных проектах. 2015.

[2] Адаменко А.А., Аветисова Е.С., Будагов И.В. Обзор наземных лазерных сканеров выпускаемых фирмой Leica Geosystems // В сборнике: Молодая наука - 2013 Mатериалы IV Открытой международной молодежной научно-практической конференции, посвященной Году охраны окружающей среды в Российской Федерации. 2014. С. 200-201.

[3] Грибкова И.С., Шерстюк Н.А. Лазерное сканирование // В сборнике: Науки о земле на современном этапе VIII Международная научно-практическая конференция. 2013. С. 53-55.

[4] Гура Т.А., Катрич А. Е. Обработка данных наземного лазерного сканирования для получения обмерных чертежей объектов культурного наследия // Молодой учёный Международный научный журнал, № 26 (130), 2016г, С. 25-28

[5] Кузнецова А.А., Гура Д.А., Алкачев Т.Э. Анализ полученных данных методом лазерного сканирования для выполнения периодического мониторинга на примере здания расположенного в г. Краснодаре // Статья в журнале: Научные труды Кубанского государственного технологического университета. 2014. № 4. С. 77-83.

[6] Шевченко Г.Г., Гура Д.А., Глазков Р.Е. Анализ программного обеспечения для обработки данных наземного лазерного сканирования // Современное промышленное и гражданское строительство. 2016. Т. 12. № 3. С. 127-140.

[7] Бушнева И.А., Безверхова А.Ю., Шевченко Г.Г., Гура Д.А. Об использовании наземного лазерного сканирования для получения фасадных чертежей исследуемых зданий и строений // Научные труды Кубанского государственного технологического университета. 2016. № 11. С. 89-97.

[8] Шевченко А.А., Глазков Р.Е., Пилюшенко А.В. Принцип работы наземной сканирующей системы // Научные труды Кубанского государственного технологического университета. 2016. № 11. С. 76-88.

[9] Шевченко Г.Г., Гура Д.А., Глазков Р.Е., Пилюшенко А.В. Технологическая схема проведения фасадной съёмки методами наземного лазерного сканирования // Сборник трудов конференции: WORLD SCIENCE: PROBLEMS AND INNOVATIONS сборник статей III Международной научно-практической конференции. Пенза, 2016. С. 107-112. 